\title{
DIREITO DE ACESSO À INFORMAÇÃO AMBIENTAL: DA FORMALIDADE À EFETIVIDADE DOS DIREITOS DE ACESSO
}

\section{THE RIGHT OF ACCESS TO ENVIRONMENTAL INFORMATION: FROM THE FORMALITY TO THE EFFECTIVENESS OF THE RIGHTS OF ACCESS}

\author{
${ }^{1}$ Andressa de Oliveira Lanchotti \\ 2Jamile Bergamaschine Mata Diz
}

\section{RESUMO}

O direito de acesso à informação ambiental está consagrado na seara dos direitos humanos como um direito político e civil, essencial à garantia do direito fundamental ao meio ambiente saudável e equilibrado. Entretanto, especialmente no contexto da sociedade de risco, a mera declaração desses direitos não se faz suficiente para garantir a sua efetividade. Nesse sentido, o presente trabalho traz uma análise da legislação brasileira relativa ao tema, no intuito de entender se a normativa pátria garante a efetividade do direito de acesso à informação ambiental, ou se o faz de maneira estritamente formal.

Palavras-chave: Direitos de Acesso, Direito Fundamental, Acesso à Informação, Acesso à Informação Ambiental, Participação Popular.

\begin{abstract}
The Right of Access to Environmental Information is enshrined in the harvest of Human Rights as a political and civil right, essential to the guarantee of the fundamental right to a healthy and balanced environment. However, especially in the context of Risk Society, the mere declaration of such rights are not enough to ensure its effectiveness. In this sense, the present work brings an analysis of the Brazilian legislation on the subject, with the intention to understand if the national normative ensures the effectiveness of the Right of Access to Environmental Information, or if it's made strictly in a formal way.
\end{abstract}

Keywords: Right of Access, Fundamental Right, Access to Information, Access to Environmental Information, Public Participation.

\footnotetext{
${ }^{1}$ Doutora em Direitos Fundamentais e Liberdades Públicas pela Universidade de Castilla-La Mancha - UCLM (Espanha). Coordenadora das Promotorias de Justiça por Bacias Hidrográficas dos Rios das Velhas e Paraopeba - MPMG, Minas Gerais (Brasil). E-mail: alanchotti@ hotmail.com

${ }^{2}$ Doutora em Direito Público/Direito Comunitário pela Universidade Alcalá - UAH (Madrid). Professora da Faculdade de Directo pela Universidade Federal de Minas Gerais - UFMG, Minas Gerais (Brasil). E-mail: jmatadiz@yahoo.com.br
} 


\section{INTRODUÇÃO}

O Direito de acesso à informação é um direito humano indispensável para o exercício da cidadania e para consolidação do Estado Democrático de Direito, juntamente com os direitos de acesso à participação e à justiça. Elencados no Pacto Internacional sobre Direitos Civis e Políticos $(1966)^{3}$, estes direitos de acesso não podem ser violados e devem ser garantidos de forma imediata, levando-se em consideração os princípios da igualdade e da não discriminação, trazidos no artigo $2^{\circ}$ do referido instrumento (CEPAL, 2016, p. 11).

Esta proteção especial dentro do sistema de direitos humanos, se dá em razão da importância desses direitos de acesso para a própria existência da democracia, bem como sua centralidade na garantia de outros direitos, na medida em que são indispensáveis para se alcançar, no âmbito da Administração Pública, boa governança, transparência, “accountability” e uma gestão pública inclusiva e participativa (CEPAL, 2016, p. 11).

Na sociedade de risco, descrita por Ulrich Beck (2002), na qual é percebida a radicalização dos processos de industrialização e de desenvolvimento técnico-científico, os riscos possuem um potencial catastrófico imensurável, ou de difícil mensuração ou controle. Em um contexto no qual os riscos ganham tamanha proporção, merece especial atenção sua consequência ambiental, em razão do caráter de irreversibilidade ou de difícil reparação dos danos ambientais.

Dessa forma, para se garantir o direito fundamental intergeracional a um ambiente saudável e equilibrado, no contexto da sociedade de risco, torna-se indispensável a garantia também dos direitos de acesso em matéria ambiental para que as pessoas possam participar dos processos deliberativos sobre a matéria. Com isso, os cidadãos dividem com o Poder Público a responsabilidade pela tomada de decisão e participam ativamente da escolha dos riscos ambientais aos quais desejam se submeter, permitindo-se ainda a defesa de outros direitos correlatos.

Em um momento no qual os direitos de acesso em matéria ambiental estão em discussão na América Latina, com os esforços coordenados pela Comissão Econômica para a América Latina e o Caribe (CEPAL) para se chegar a um acordo regional sobre acesso à

\footnotetext{
${ }^{3}$ Este Pacto foi ratificado pelo Brasil por meio do Decreto nº 592/1992.
} 
informação, participação popular na tomada de decisão e acesso à justiça, apresenta-se uma oportunidade única de análise e revisão da legislação brasileira sobre o tema, para que se possa identificar as principais falhas e problemas, e então avançar no sentido de efetivarem-se os direitos de acesso à informação, participação e acesso à justiça em matéria ambiental.

O direito de acesso à informação ambiental, objeto de análise do presente estudo, foi, na Declaração Universal dos Direitos Humanos (art. 19), em 1948, o primeiro direito de acesso reconhecido por um instrumento internacional. Também possui a maior previsão expressa no ordenamento jurídico pátrio, pois presente na Constituição da República de 1988 (artigo $5^{\circ}$, inciso XXXIII) e em lei específica, conhecida por Lei de Acesso à Informação Ambiental (Lei ${ }^{\circ}$ 10.650/2003).

O presente estudo analisará os principais instrumentos internacionais que delimitaram e desenvolveram os direitos de acesso à informação, participação e justiça, sobretudo relativos ao acesso à informação ambiental, a partir da concepção de sociedade de risco descrita por Ulrich Beck (2002), com suas implicações sobre os riscos em matéria ambiental e a relação com os direitos de acesso. Além disso, deverá ser examinado o tratamento deste importante princípio no ordenamento jurídico brasileiro no que se refere ao acesso à informação ambiental, sobretudo no âmbito da participação popular nos processos decisórios, buscando estabelecer uma vertente crítica sobre a legislação brasileira.

A metodologia de trabalho concentrou-se nos aspectos principais estabelecidos para uma pesquisa relativa ao Direito Ambiental, devido especialmente ao caráter fragmentado da normativa e institucionalidade constatada na produção e aplicação de normas ambientais. Neste sentido, foram utilizados métodos que permitiram analisar a evolução da normativa ambiental, especificamente dos princípios gerais, e sua consequente incorporação ou "absorção" pelo sistema jurídico nacional.

Desta forma, o método histórico possibilitou analisar como se deu o desenvolvimento e consolidação dos direitos de acesso como direitos humanos, sobretudo o direito de acesso à informação ambiental, bem como o desenvolvimento do direito de acesso à informação ambiental no direito brasileiro. O método dedutivo foi adotado para determinar se a normativa brasileira sobre o tema tratado é capaz de dar efetividade ao direito humano fundamental de acesso à informação ambiental, dado seu caráter de direito civil e político. 


\section{ACESSO À INFORMAÇÃO AMBIENTAL NA SOCIEDADE DE RISCO}

O estágio atual de desenvolvimento da modernidade tem sido acompanhado de um aprofundamento e radicalização do processo de industrialização e de desenvolvimento técnico e científico, elevando os riscos aos quais as sociedades são expostas a níveis catastróficos e até então inéditos na proporção em que se desenham (Beck, 2002). Este momento histórico, descrito por Ulrich Beck (2002), tem sido classificado como modernidade tardia, segunda modernidade, ou sociedade do risco (Bahia, 2012).

Nesta abordagem proposta, a narrativa histórica e social do próprio risco também encontra-se em disputa. O estudo do risco nas ciências sociais desenvolve-se alicerçado no debate científico entre diferentes vertentes (Bahia, 2012, p. 30 - 46), com destaque para a perspectiva construcionista do risco.

Apesar de inserida em uma disputa científico-ideológica de narrativa e conceituação do risco, com suas limitações e críticas possíveis, autores como Douglas; Wildavsky (1983) e Hannigan (2009) aprofundaram a percepção de o risco ser uma construção política, social e coletiva, desde sua identificação até a escolha de seu nível de tolerabilidade, dentro da coletividade em que cada um desses riscos se insere. ${ }^{4}$

Entretanto, não se pode perder o horizonte da análise técnico-científica do risco. Estas duas perspectivas, sobretudo, precisam caminhar juntas. A este respeito, afirma Bahia:

\footnotetext{
Não se pode negar hoje que o risco é uma construção sociocultural, embora não possa ficar confinado nas percepções e construções sociais. Nesse sentido, as análises técnicas do risco também podem ser compreendidas como parte integrante do seu processo de construção social. (Bahia, 2012, p.39)
}

Portanto, a percepção e a forma de lidar com o risco não podem tomar lugar sem considerar, de um lado, as percepções e posicionamentos da coletividade a respeito daquele risco assumido e entendido como tal e, de outro, as percepções técnicas e científicas a seu respeito.

O que se percebe na sociedade de risco, contrariamente, é a alienação dos cidadãos em relação aos processos decisórios de definição dos rumos da ciência e do progresso (Hermitte, 2005, p. 16). Bahia (2012, p. 75), ao tratar do tema, preconiza que "se, por um

\footnotetext{
${ }^{4}$ Ver também Lieber; Romano-Lieber (2002) e Viegas (2007)
} 
lado, é impossível, para ele [o cidadão], escapar de uma nuvem tóxica ou radioativa, por outro, não lhe é dado o direito de participar do processo de tomada de decisão."

O advento da sociedade de risco alterou a dinâmica política de definição dos rumos da ciência e do progresso. Nesse aspecto, o acesso amplo à informação e a participação popular tornam-se fundamentais para a legitimação e a democratização das escolhas estatais e dos grupos de atuação, como cientistas e empreendedores, relacionadas ao progresso e ao desenvolvimento das ciências e tecnologias. (Hermitte, 2005, p. 20-21 e Beck, 1998, p. 281283).

No atual contexto da modernidade, aqui brevemente referenciado, deve-se concretizar uma democracia ecológica fundada na participação cidadã e no debate entre os diversos grupos de interesse para a tomada de decisão acerca dos rumos da economia e do progresso científico, e sua consequente assumpção de riscos pela sociedade. (Goldblatt, 1996, p. 237).

Especificamente no que se diz respeito aos riscos que envolvam alterações significativas no meio ambiente, a democratização do processo decisório de assumpção desses riscos faz-se indispensável, tanto em razão do caráter de irreversibilidade ou de difícil apuração e reparação do dano ambiental, quanto em razão do direito fundamental intergeracional a um ambiente sadio e equilibrado.

Nesse momento, os direitos de acesso, sobretudo o direito de acesso à informação ambiental, ganham relevância indiscutível. Eles se constituem no principal caminho possível para a democratização dos processos de definição dos riscos a serem assumidos pela própria sociedade. Na sociedade de risco, o acesso amplo e irrestrito à informação ambiental se faz fundamental, para que o exercício da cidadania e a participação ativa dos cidadãos ocorra de forma instruída e capacitada.

Sem dúvida, a ciência desenvolve um importante papel na gestão dos riscos, fornecendo informações valiosas, que auxiliam a tomada de decisão. Todavia, decidir qual espécie de risco será ou não admissível assumir, ou seja, quais ações humanas capazes de transformar o risco em realidade deverão ou não ser colocadas em prática, não é uma tarefa exclusiva dos cientistas e deve ser compartilhada com a sociedade. Nesse sentido, consideramos a gestão dos riscos mais que uma questão cientifica, pois consiste também em um problema social e cultural (LANCHOTTI, 2014, p. 254). 


\subsection{ACESSO À INFORMAÇÃO AMBIENTAL NO DIREITO INTERNACIONAL}

Os chamados "direitos de acesso" (CEPAL, 2016, p. 12), como são denominados os direitos de acesso à informação, à participação e à justiça, são ainda direitos civis e políticos estabelecidos no Pacto Internacional sobre Direitos Civis e Políticos de 1966, ratificado pelo Brasil por meio do Decreto ${ }^{\circ}$ 592/1992. Dentre estes, o direito de acesso à informação se apresenta como o mais antigo e mais amplamente estabelecido como direito humano por diversos acordos e convenções internacionais.

A Declaração Universal de Direitos Humanos de 1948, em seu art. 19, declarou o direito a "procurar, receber e difundir informações", inerente à liberdade de expressão. Desde então, diversos instrumentos reconheceram o acesso à informação como direito humano (CEPAL, 2016, p. 13). Entre eles, destacam-se o artigo 19 do Pacto Internacional sobre Direitos Civis e Políticos de 1966, o artigo 13 da Convenção sobre os Direitos da Criança de 1989, o artigo 13 da Convenção Internacional sobre a Proteção dos Direitos de Todos os Trabalhadores Migrantes e dos Membros das suas Famílias de 1990, o capítulo 40 da Agenda 21, o artigo 17 da Convenção sobre Diversidade Biológica e o artigo 18 da Convenção Internacional de Combate à Desertificação.

Em 2013, um relatório da Relatoria Especial das Nações Unidas sobre a Proteção e Promoção do Direito à Liberdade de Opinião e Expressão afirmou que o direito de acesso à informação é uma condição indispensável para que sociedades possam ser consideradas livres e democráticas, e que a sua não observância pode comprometer não somente o acesso a direitos civis e políticos, mas também a direitos econômicos, sociais e culturais. Ressaltou, ainda, a centralidade do acesso à informação para a realização adequada de elementos fundamentais para um regime democrático, citando inclusive a promoção de processos participativos de tomada de decisão.

Logo, percebe-se que foi justamente no intuito de permitir a circulação de informações no sentido governo - cidadãos, que surge e consolida-se o direito ao acesso à informação, uma vez que compreende uma parte significativa para o desenvolvimento da pessoa em sua totalidade, inerente a todos os seres humanos de quaisquer povos. Quatro seriam as características necessárias para se configurar uma informação adequada ao intuito 
de respaldar o direito ao seu acesso: a veracidade, a amplitude, a tempestividade e a acessibilidade (Sampaio, 2003). Segundo Pastor e Gasó (2008), o direito ao acesso à informação possui três funções básicas e complementares: a primeira função corresponde ao âmbito individual do titular do referido direito, que busca satisfazer seu interesse sobre uma informação independentemente de suas razões. A segunda função possui uma dimensão objetiva, na medida em que influencia o modo de funcionamento da Administração Pública e implica na melhoria da transparência e da eficácia. E por fim, o direito ao acesso à informação permite a aquisição de conhecimento pelo indivíduo, que poderá ser utilizado na defesa de seus direitos ou interesses (Mata Diz e Discacciati, 2015).

Já Amado (2010) analisa duas dimensões do acesso à informação: primeiramente, a objetiva, que corresponde ao controle da transparência do Poder Público, com a justificativa para suas decisões e processos administrativos; e a subjetiva, na medida em que o cidadão compreende os fundamentos e o limite de seus direitos perante as autoridades públicas.

No que se refere ao acesso à informação ambiental no plano internacional, especificamente, a Conferência Mundial sobre o Homem e o Meio Ambiente (1972), realizada na cidade de Estocolmo, Suécia, fundamentou os pilares do tema em seu artigo 19, conforme tradução livre:

\footnotetext{
É indispensável um esforço para a educação em questões ambientais, dirigida tanto às gerações jovens como aos adultos e que preste a devida atenção ao setor da população menos privilegiado, para fundamentar as bases de uma opinião pública bem informada, e de uma conduta dos indivíduos, das empresas e das coletividades inspirada no sentido de sua responsabilidade sobre a proteção e melhoramento do meio ambiente em toda sua dimensão humana. É igualmente essencial que os meios de comunicação de massas evitem contribuir para a deterioração do meio ambiente humano e, ao contrário, difundam informação de caráter educativo sobre a necessidade de protegê-lo e melhorá-lo, a fim de que o homem possa desenvolver-se em todos os aspectos.
}

Vinte anos mais tarde, a Conferência das Nações Unidas sobre o Meio Ambiente e o Desenvolvimento, sediada no Rio de Janeiro (Rio-92), também representou um marco relevante para a consolidação do direito ao acesso à informação ambiental, sobretudo com a adoção explícita dos três direitos de acesso para questões relativas ao meio ambiente.

Dessa forma, o Princípio 10 estabeleceu os três pilares da participação pública em matéria ambiental: acesso à informação, influência da participação popular na tomada de decisão e acesso à justiça, nos seguintes termos: 
A melhor maneira de tratar as questões ambientais é assegurar a participação, no nível apropriado, de todos os cidadãos interessados. No nível nacional, cada indivíduo terá acesso adequado às informações relativas ao meio ambiente de que disponham as autoridades públicas, inclusive informações acerca de materiais e atividades perigosas em suas comunidades, bem como a oportunidade de participar dos processos decisórios. Os Estados irão facilitar e estimular a conscientização e a participação pública, colocando as informações à disposição de todos. Será proporcionado o acesso efetivo a mecanismos judiciais e administrativos, inclusive no que se refere à compensação e reparação de danos.

Assim, o Princípio 10 da Declaração do Rio consolidou os fundamentos principiológicos sobre os quais deveriam se desenvolver, em nível nacional e internacional, os instrumentos de participação pública em matéria ambiental, inclusive no que diz respeito ao acesso à informação ambiental, confirmando a adoção dos direitos humanos de acesso para a proteção do direito ao meio ambiente sadio e equilibrado.

Desta feita, em 1998, na cidade de Aarhus, Dinamarca, a Comunidade Europeia e seus Estados-Membros adotaram a primeira convenção internacional com o intuito de endereçar a participação pública introduzida pelo Princípio 10 da Declaração do Rio: a Convenção sobre acesso à informação, participação do público no procedimento de tomada de decisão e acesso à Justiça em matéria de Ambiente (Convenção de Aarhus).

Ao entrar em vigor em outubro de 2001, a Convenção de Aarhus afirmou-se como a primeira convenção a desenvolver os três pilares da participação pública apresentados pelo Princípio 10 transcrito anteriormente (Sands, 2003). Até o dia 05 de fevereiro de 2016, a Convenção continha 47 Estados signatários.

Os três aspectos da participação pública ganharam notoriedade como sendo os três “pilares” da Convenção de Aarhus (Müllerová, 2013). Estes três pilares seriam, desta forma, interdependentes, e igualmente essenciais para garantir a efetividade da participação pública na tomada de decisão em matéria ambiental, bem como para promover um maior envolvimento da sociedade civil e o aprimoramento do senso de responsabilidade sobre as consequências das decisões políticas em questões de ambiente. (Müllerová, 2013).

$\mathrm{O}$ artigo $4^{\circ}$ da Convenção de Aarhus trata especificamente do pilar referente ao acesso à informação. Este artigo prevê que todo cidadão, sem necessidade de provar interesse específico sobre a matéria, tenha acesso às mesmas informações das quais dispõem as 
autoridades públicas ${ }^{5}$, na forma requerida e dentro do prazo máximo de um mês, ressalvadas algumas exceções trazidas pelo próprio artigo $4^{\circ}$.

No art. $5^{\circ}$, a Convenção estabelece obrigações para os Estados relativas à organização, publicidade e divulgação das informações, de forma que não seja utilizada a justificativa de não possuírem os dados requeridos como forma de restrição do direito à informação. (Müllerová, 2013)

Portanto, os aspectos apresentados a respeito do direito de acesso à informação pela Convenção de Aarhus representaram um avanço indiscutível no âmbito da participação pública em matéria ambiental, sendo o instrumento internacional que mais desenvolveu o tema até então.

Mais recentemente, a Conferência das Nações Unidas sobre Desenvolvimento Sustentável, conhecida como Rio + 20, abordou em alguns itens de seu documento final, a participação pública a partir da perspectiva tríplice de acesso à informação, de influência na tomada de decisão e do acesso à justiça, a exemplo do parágrafo. 43 do documento:

\begin{abstract}
Ressaltamos que uma ampla participação pública e o acesso à informação e às instâncias judiciais e administrativas são indispensáveis para a promoção do desenvolvimento sustentável. O desenvolvimento sustentável requer o envolvimento e a participação ativa e concreta dos órgãos legislativos e judiciários nos níveis regional, nacional e subnacional, assim como o envolvimento de todos os grandes grupos: mulheres, crianças e jovens, povos indígenas, organizações não governamentais, autoridades locais, trabalhadores e sindicatos, empresas e setores de atividades, a comunidade científica e tecnológica e os agricultores, bem como outras partes interessadas, incluindo as comunidades locais, os grupos de voluntários e as fundações, os migrantes, as famílias, os idosos e as pessoas com deficiência. Nesse sentido, resolvemos trabalhar de uma forma mais estreita com os grandes grupos e outros interessados e incentivá-los a participar ativamente, conforme o caso, em processos que contribuam com as decisões envolvendo as políticas e programas de desenvolvimento sustentável, seu planejamento e implementação, em todos os níveis.
\end{abstract}

\footnotetext{
${ }^{5}$ Nos termos do art. $2^{\circ}$ da Convenção, a definição de autoridade pública é:

“a) Um Governo a nível nacional, regional ou outro;

b) Pessoas singulares ou colectivas que desempenhem funções da administração pública, nos termos das disposições do direito interno, incluindo o exercício de deveres específicos, a realização de actividades ou a prestação de serviços relacionados com o ambiente;

c) Quaisquer outras pessoas singulares ou colectivas com responsabilidades públicas, que desempenhem funções públicas ou que prestem serviços públicos relacionados com o ambiente, sob o controlo de um organismo ou de uma entidade referida nas alíneas a) ou b);

d) As instituições das organizações de integração económica regional referidas no artigo $17^{\circ}$ que sejam Parte na presente Convenção.

Esta definição não inclui organismos ou instituições que actuem na qualidade de órgãos jurisdicionais ou legislativos;" Disponível em: < http://www.unece.org/fileadmin/DAM/env/pp/EU\%20texts/ conventioninportogese.pdf>. Acesso em 26. Fev. 2016.
} 
$\mathrm{Na}$ própria conferência Rio +20 , foi definido um grupo de trabalho para a construção de um acordo regional sobre o princípio 10 da Rio-92, no âmbito da América Latina e Caribe. A CEPAL, naquela oportunidade, assumiu a secretaria técnica na negociação deste acordo, e têm conduzido os trabalhos desde então. $\mathrm{O}$ acordo tem previsão para ser concluído em dezembro de 2016 e seus documentos preliminares já demonstram uma tratativa avançada e atual sobre o acesso à informação, bem como reconhecem a importância da educação ambiental para se assegurar os direitos de acesso, sobretudo o direito de acesso à informação.

\section{O ACESSO À INFORMAÇÃO AMBIENTAL NO DIREITO BRASILEIRO}

No sentido de confirmar a relevância e centralidade do direito de acesso à informação para o Estado Democrático de Direito e seus cidadãos, a Constituição Brasileira de 1988 previu em seu artigo $5^{\circ}$, inciso XXXIII, que:

Todos têm direito a receber dos órgãos públicos informações de seu interesse particular, ou de interesse coletivo ou geral, que serão prestadas no prazo da lei, sob pena de responsabilidade, ressalvadas aquelas cujo sigilo seja imprescindível à segurança da sociedade e do Estado.

De toda forma, mesmo anteriormente à Carta Constitucional de 1988, o Estado brasileiro já havia reconhecido o direito de acesso à informação, bem como sua aplicabilidade às matérias ambientais. A Lei $n^{\circ}$. 6.938/81, que trata da Política Nacional do Meio Ambiente, já previa a divulgação de dados e informações ambientais para a formação da consciência pública sobre a necessidade de preservação da qualidade do meio ambiente e do equilíbrio ecológico (art. $\left.4^{\circ}, \mathrm{V}\right) . \mathrm{O}$ artigo $9^{\circ}$ desta mesma lei estabeleceu que dentre os instrumentos da Política Nacional do Meio Ambiente está a prestação de informações relativas ao meio ambiente.

No mesmo sentido, o Decreto 98.161/1989, que se ocupa da administração do Fundo Nacional do Meio Ambiente, previu, no artigo $6^{\circ}$, que compete à Comissão que administra o fundo "desenvolver o relatório anual de atividades para promover a sua difusão". Além da legislação referida, alguns instrumentos internacionais ratificados pelo Brasil e já apresentados no presente trabalho, possuem força de lei, com seus textos trazidos ao ordenamento interno por meio de decretos presidenciais. A exemplo, têm-se a Convenção sobre Diversidade Biológica, ratificada pelo Brasil pelo Decreto 2.519/1998, a Convenção 
Internacional de Combate à Desertificação, também ratificada pelo Brasil por meio do Decreto 2.741/1998, e o Pacto Internacional sobre Direitos Civis e Políticos de 1966, ratificado pelo Brasil por meio do Decreto ${ }^{\circ}$ 592/1992.

Principal instrumento normativo sobre o assunto, a Lei $\mathrm{n}^{\circ} 10.650 / 2003$, conhecida como Lei de Acesso à Informação Ambiental, “dispõe sobre o acesso público aos dados e informações existentes nos órgãos e entidades integrantes do Sisnama".

Influenciada pela repercussão do princípio 10 da Rio-92 e da Convenção de Aarhus, esta lei significou avanços importantes na efetivação do direito ao acesso à informação em matéria ambiental.

Inspirada nas inovações trazidas pela Convenção de Aarhus, a Lei de Acesso à Informação Ambiental garante o acesso às informações presentes nos órgãos do Sistema Nacional de Meio Ambiente - Sisnama a qualquer indivíduo, independentemente de comprovação de interesse específico, dentro do prazo de trinta dias, devendo sua recusa ser devidamente motivada. Contendo ainda outros avanços importantes, destaca-se o art. $4^{\circ}$ da referida lei que traz menção expressa ao direito de acesso à informação ${ }^{6}$.

Ao realizarem estudo comparativo entre a Lei e a Convenção de Aarhus assim destacam Mata Diz e Discacciati (2015, pp. 105-106)

\begin{abstract}
A Lei n ${ }^{\circ} 10.650 / 2003$ possui a temática restrita ao primeiro pilar da Convenção de Aarhus, ou seja, contém artigos semelhantes sobre informação ambiental, mas não assegura a participação popular na tomada de decisões e o acesso à justiça em matéria ambiental. Contudo, em matéria de acesso à informação ambiental, a lei brasileira foi um avanço e trouxe embasamento legal para um maior engajamento social. O impacto da ordem internacional, representado pela influência da Convenção de Aarhus na Lei n ${ }^{\circ} 10.650 / 2003$ é evidente. A lei nacional poderia ser mais abrangente, para incluir pessoas jurídicas como potenciais requerentes, ou reconhecer o papel das ONGs, porém os parâmetros estipulados correspondem a uma democracia que promove a ecocidadania, muito embora tais direitos não sejam efetivamente usufruídos
\end{abstract}

\footnotetext{
${ }^{6}$ Art. $4^{\circ}$ Deverão ser publicados em Diário Oficial e ficar disponíveis, no respectivo órgão, em local de fácil acesso ao público, listagens e relações contendo os dados referentes aos seguintes assuntos:

I- pedidos de licenciamento, sua renovação e a respectiva concessão;

II- pedidos e licenças para supressão de vegetação;

III- autos de infrações e respectivas penalidades impostas pelos órgãos ambientais;

IV- lavratura de termos de compromisso de ajustamento de conduta;

$\mathrm{V}$ - reincidências em infrações ambientais;

VI- recursos interpostos em processo administrativo ambiental e respectivas decisões;

VII- registro de apresentação de estudos de impacto ambiental e sua aprovação ou rejeição.

Parágrafo único. As relações contendo os dados referidos neste artigo deverão estar disponíveis para o público trinta dias após a publicação dos atos a que se referem.
} 
Além disso, deve-se mencionar que somente o Brasil e a Argentina foram, até recentemente, os únicos países de toda a América Latina e Caribe a criarem leis específicas dispondo sobre o acesso à informação ambiental (CEPAL, 2013, p. 73). Não obstante, a Lei de Acesso à Informação Ambiental brasileira mostra-se insuficiente para assegurar a efetividade deste direito de acesso.

De início, pode-se mencionar que a referida lei garante acesso a dados e informações existentes apenas nos órgãos do Sisnama, não abrangendo outras possíveis fontes de informação ambiental, como os órgãos dos poderes legislativo e judiciário, ou até mesmo outros órgãos do poder executivo.

Outro problema apresentado pelo citado instrumento normativo, diz respeito a este estar em descompasso com o atual estágio de evolução das tecnologias da comunicação, que disponibilizam à sociedade instrumentos que permitem de forma mais célere e eficaz o acesso à informação. Não se pode mais assegurar o acesso à informação ambiental com a simples publicação de informações no Diário Oficial, instrumento de alcance questionável.

Em um cenário no qual grande parcela da população têm amplo acesso à rede mundial de computadores e utiliza de redes sociais para comunicação diária, é recomendável que estas plataformas sejam utilizadas pelo poder público para melhorar a divulgação e o acesso às informações sobre meio ambiente.

Portanto, apesar de a Lei de Acesso à Informação Ambiental ter apresentado conquistas importantes na consolidação desse direito de acesso, tal lei não se mostra suficiente para garantir sua efetividade. Torna-se indispensável e urgente, nesse sentido, sua atualização e melhoria, sob pena de o Estado Brasileiro continuar a cercear este direito humano, indispensável para a consolidação do Estado Democrático Socioambiental de Direito instituído formalmente com a promulgação da Constituição Federal de 1988.

\section{EDUCAÇÃO AMBIENTAL COMO INSTRUMENTO DE ACESSO À INFORMAÇÃO E AO DESENVOLVIMENTO SUSTENTÁVEL}

Para Canotilho (1993) o direito de acesso à informação seria composto por três diferentes patamares: o direito de informar, representando a liberdade de transmitir ou comunicar informações; o direito de se informar, sendo este a liberdade de buscar as 
informações sem sofrer impedimentos; e o direito de ser informado, representando a necessidade de os detentores de informação (Poder Público, agentes econômicos e meios de comunicação) fornecerem informações constantes e verídicas.

Entretanto, a mera prestação de informações ou o acesso a estas informações, requeridas ou não de forma direta pelos cidadãos, não pode ser suficiente para a efetivação do direito ora em comento.

Sobretudo, a necessidade de aperfeiçoar-se a participação pública perpassa a capacidade e os instrumentos disponíveis para que as pessoas absorvam as informações prestadas pelas autoridades públicas. Nesse contexto, não se pode ignorar a multidão de analfabetos existentes nos países pobres e em desenvolvimento, sobretudo nos países da América Latina, com o que se torna indispensável a garantia do direito à educação ambiental para que as mais diversas camadas sociais possam participar de maneira efetiva das decisões sobre o meio ambiente.

Sobre o papel fundamental da educação na formação de cidadãos preparados para a participação pública na tomada de decisão, lecionou Paulo Freire:

\begin{abstract}
As crianças precisam crescer no exercício desta capacidade de pensar, de indagar-se e de indagar, de duvidar, de experimentar hipóteses de ação, de programar e de não apenas seguir os programas a elas, mais do que propostos, impostos. As crianças precisam de ter assegurado o direito de aprender a decidir, o que se faz decidindo. Se as liberdades não se constituem entregues a si mesmas, mas na assunção ética de necessários limites, a assunção ética desses limites não se faz sem riscos a serem corridos por elas e pela autoridade ou autoridades com que dialeticamente se relacionam. (FREIRE, 2014, p. 63-64) [grifo nosso]
\end{abstract}

Nesse sentido, o próprio art. 225 da Constituição da República de 1988 preconiza a importância da educação ambiental, como incumbência do Poder Público, indispensável à garantia do direito ao meio ambiente equilibrado:

\footnotetext{
$\S 1^{\circ}$ Para assegurar a efetividade desse direito, incumbe ao Poder Público:

(...)

VI - promover a educação ambiental em todos os níveis de ensino e a conscientização pública para a preservação do meio ambiente.
}

Assim, em 1999, foi instituída a Política Nacional de Educação Ambiental, por meio da Lei 9.795 e de seu Decreto Regulamentador 4.281/2002. Esta lei definiu educação ambiental como sendo:

os processos por meio dos quais o indivíduo e a coletividade constroem valores sociais, conhecimentos, habilidades, atitudes e competências voltadas para a conservação do meio ambiente, bem de uso comum do povo, essencial à sadia qualidade de vida e sua sustentabilidade. (art. $\left.1^{\circ}\right)$ 
Como demonstrado por MILARÉ (2011), a Educação Ambiental, bem como seus princípios e práticas, já vinham sendo objeto de debate no âmbito das Nações Unidas, a exemplo da Conferência de Belgrado (1975), da Primeira Conferência Intergovernamental sobre Educação Ambiental de Tbilisi, na Geórgia, antiga União Soviética (1977), do Seminário sobre Educação Ambiental na Costa Rica (1979), do Congresso Internacional sobre Educação e Formação Ambientais em Moscou (1987), do Seminário Latino-Americano de Educação Ambiental na Argentina (1988), além da Eco-92, com o capítulo 36 da Agenda 21.

Apesar de definir objetivos já bem desenvolvidos e amplamente discutidos no âmbito da Educação Ambiental, a efetividade da Lei 9.795/1999 ainda se mostra incipiente. Muitas instituições públicas de ensino não contêm diretrizes para adoção da educação ambiental como uma prática educativa integrada, contínua e permanente em seus programas, conforme enunciado pelo art. 10 da Lei de Educação Ambiental.

A referida lei ainda ressalta que "a educação ambiental é um componente essencial e permanente da educação nacional, devendo estar presente, de forma articulada, em todos os níveis e modalidades do processo educativo, em caráter formal e não-formal” (Art. $2^{\text {o }}$, Lei 9.795/1999). Portanto, o combate ao analfabetismo deve ocorrer em consonância com a educação ambiental, medida esta que se faz indispensável para a inclusão de todos cidadãos nas esferas de tomada de decisão em matéria de meio ambiente.

Importante ainda destacar a distinção entre os conceitos de "espaços de educação ambiental" e "canais de educação ambiental”, trazidos por Aguiar Coimbra (2000), para quem os espaços de educação ambiental seriam os espaços nos quais o conteúdo educacional é efetivamente desenvolvido (escolas, espaços de debate, associações, etc.), e os canais de educação, por sua vez, seriam os meios pelos quais são transmitidas as informações com intuito, no máximo, de conscientização (mídia, campanhas de conscientização), nos quais a educação não se faz completa.

Para Milaré (2011), em acertado posicionamento a respeito da Educação Ambiental, esta "passa a constituir um direito do cidadão, assemelhado aos direitos fundamentais, porquanto estreitamente ligado aos direitos e deveres constitucionais da cidadania", indispensável à efetividade do acesso à informação em matéria ambiental, bem como aos demais direitos de acesso. 


\section{CONCLUSÃO}

O acesso à informação é direito humano fundamental, classificado como direito civil e político, garantido pela $\mathrm{CR} / 88$, componente indispensável e indissociável dos demais direitos de acesso em matéria ambiental.

No contexto da sociedade de risco, na qual os riscos ganham proporções catastróficas e de difícil mensuração, para que se garanta a defesa do direito ao meio ambiente saudável e equilibrado para as presentes e futuras gerações, o direito de acesso à informação em matéria ambiental é indispensável e urgente.

Apesar de o Brasil dispor de legislação específica sobre o acesso à informação em matéria de meio ambiente, observa-se a existência de sérios problemas que comprometem a efetividade deste direito.

Estes problemas precisam ser enfrentados e superados, sob o risco de o acesso à informação perpetuar-se no ordenamento jurídico brasileiro como uma garantia estritamente formal, presente na letra da lei, mas sem materialização na realidade.

Dentre os problemas identificados no presente trabalho e que devem ser superados, destaca-se o fato de a lei que rege o acesso aos dados e informações ambientais (Lei 10.650/2003) garantir o acesso do público aos dados e informações existentes apenas nos órgãos do Sisnama, sem contemplar outras possíveis fontes de informação ambiental. A inexistência de norma jurídica que garanta o amplo acesso à informação ambiental em qualquer órgão público é uma lacuna que não deve persistir no ordenamento jurídico brasileiro.

Do mesmo modo, a modalidade de publicidade dos dados prevista pela Lei de Acesso à Informação Ambiental mostra-se restrita e ultrapassada, pois contempla a utilização de instrumentos de acessibilidade limitados, a exemplo do Diário Oficial. Torna-se indispensável, no atual contexto de desenvolvimento e acessibilidade tecnológica, a publicidade de dados e a possibilidade de acesso à informação por meio da utilização da rede mundial de computadores. Isto se daria com o aproveitamento das redes sociais institucionais dos órgãos públicos e empresas, quando envolvidas, além da exploração de outros mecanismos de comunicação já utilizados pelas instituições de direito público ou privado. 
Outro aspecto que evidencia o atraso da legislação de regência da matéria é o não reconhecimento explícito da educação ambiental como instrumento indispensável à efetividade do direito à informação ambiental. Este reconhecimento é uma necessidade urgente, dada a realidade social brasileira e o elevado déficit educacional de grande parte da população, bem como a falta de educação ambiental voltada para a participação nos processos decisórios, que ultrapassa os problemas já existentes em razão do analfabetismo.

Apesar disso, os contornos da educação ambiental encontram-se bem estabelecidos na Constituição da República de 1988 e na Lei 9.795/1999. Mesmo com sua incipiente aplicação, a Política Nacional de Educação Ambiental é um instrumento poderoso que precisa ser colocado em prática por todos os setores da sociedade. Neste aspecto, inclui-se as instituições de ensino, órgãos públicos e em especial os órgãos ambientais licenciadores, que necessitam desenvolver diretrizes para que a educação ambiental seja observada também no âmbito da avaliação de impacto ambiental, pois trata-se de um instrumento necessário para a garantia do direito à informação ambiental.

A efetividade da Lei 9.795/1999 depende, pois, de um esforço conjunto do poder público e da sociedade no combate ao analfabetismo e no aprimoramento da educação como um todo, medidas essas indispensáveis para a inclusão de todos cidadãos nas diversas esferas de tomada de decisão em matéria de meio ambiente.

Com um iminente acordo regional sobre os direitos de acesso em matéria de meio ambiente na América Latina e Caribe, torna-se necessária a revisão e atualização da legislação brasileira, para que esta possa garantir a efetividade destes direitos civis e políticos, bem como servir de modelo para os demais países da região, na criação de suas normas internas.

A superação dos problemas apontados pelo presente trabalho significará um importante passo no sentindo do fortalecimento da participação pública em meio ambiente, com a efetivação de um de seus três pilares: o acesso à informação em matéria ambiental. 


\section{REFERÊNCIAS BIBLIOGRÁFICAS}

AMADO, Carla Gomes. A caminho de uma ecocidadania. Notas sobre o direito à informação ambiental. In: Responsabilidade civil: Direito à Informação. Coleção Doutrinas Essenciais Responsabilidade Civil, vol. 8. NERY JUNIOR, Nelson, NERY, Rosa Maria de Andrade (org.). São Paulo: Revista dos Tribunais, 2010, pp. 221-248.

BAHIA, Carolina Medeiros. Nexo de causalidade em face do risco e do dano ao meio ambiente: elementos para um novo tratamento da causalidade no sistema brasileiro de responsabilidade civil ambiental. 2012. Tese (Doutorado em Direito). Faculdade de Direito. Universidade Federal de Santa Catarina. Florianópolis, 2012.

BECK, Ulrich. La sociedad del riesgo global. Madrid: Siglo Veintiuno de España Editores S.A., 2002.

BRASIL. Constituição da República Federativa do Brasil de 1988. Promulgada em 5 de outubro de 1988. Disponível em http://www.planalto.gov.br/ccivil_03/constituicao/ constituição.htm. Acesso em 20.04.2016.

BRASIL. Decreto No 592, de 06 de julho de 1992. Atos Internacionais. Pacto Internacional sobre Direitos Civis e Políticos. Promulgação. Disponível em: http://www.planalto.gov.br/ccivil_03/decreto/1990-1994/d0592.htm. Acesso em 08.09.2016.

BRASIL. Lei No 10.650, de 16 de abril de 2003. Dispõe sobre o acesso público aos dados e informações existentes nos órgãos e entidades integrantes do Sisnama. Disponível em: http://www.planalto.gov.br/ccivil_03/Leis/2003/L10.650.htm. Acesso em

20.04.2016.

BRASIL. Lei $\mathbf{N}^{\mathbf{0}}$ 6.938, de 31 de agosto de 1981. Dispõe sobre a Política Nacional do Meio Ambiente, seus fins e mecanismos de formulação e aplicação, e dá outras providências. Disponível em: http://www.planalto.gov.br/ccivil_03/Leis/ L6938.htm. Acesso em 20.04.2016.

BRASIL. Lei No 9.795, de 27 de abril de 1999. Dispõe sobre a educação ambiental, institui a Política Nacional de Educação Ambiental e dá outras providências. Disponível em: http://www.planalto.gov.br/ccivil_03/LEIS/L9795.htm. Acesso em 20.04.2016.

CANOTILHO, J. J. Gomes; MOREIRA, Vital. Constituição da República Portuguesa Anotada. 3. ed. rev. Coimbra: Coimbra Editora. 1993.

CEPAL. Extractos de Acceso a la información, participación y justicia en temas ambientales en América Latina y el Caribe: Situación actual, perspectivas y ejemplos de buenas prácticas. Valeria Torres. 2013. Disponível em: http://repositorio.cepal.org/bitstream/handle/11362/37791/LCM23_es.pdf?sequence=1\&isAll owed=y. Acesso em 07.09.2013. 
CEPAL. Estándares Internacionales de Derechos Humanos Aplicables Al Acesso a la Información, la Participación Pública y al Acesso a la Justicia. Resumen Executivo. 22 de março de 2016.2 Disponível em: http://repositorio.cepal.org/bitstream/handle/11362/40415/S1600291_es.pdf?sequence=1\&isA llowed=y. Acesso em 07.09.2016.

COIMBRA, José de Ávila Aguiar. Considerações para elaboração de projetos em educação ambiental. In: Educação ambiental: desenvolvimento de cursos e projetos. São Paulo: Universidade de São Paulo/ Faculdade de Saúde Pública/ Núcleo de Informações em Saúde Ambiental. Ed. 2000.

DOUGLAS, Mary; WILDAVSKY, Aaron. Risk and culture: an essay on the selection of. technological and environmental dangers. Berkeley and Los Angeles: University of California, 1983.

FREIRE, Paulo. Pedagogia da indignação: cartas pedagógicas e outros escritos. Segunda Carta, Do direito e do dever de mudar o mundo. 1. ed. São Paulo: Paz e Terra. 2014.

GOLDBLATT, David. Teoria social e meio ambiente. Lisboa: Instituto Piaget, 1996.

HANNIGAN. Sociologia ambiental. Petrópolis: Editora Vozes, 2009 (Coleção Sociologia).

HERMITTE, M-A. Os fundamentos jurídicos da sociedade de risco: uma análise de U. Beck. In: VARELLA, Marcelo Dias (org.). Governo dos riscos (Rede Latino Americana Européia sobre Governo de Riscos). Brasilia: 2005.

LANCHOTTI, Andressa de Oliveira. Evaluación de impacto ambiental y desarrollo sostenible. Belo Horizonte. Arraes Editores. 2014.

LIEBER, Renato Rocha; ROMANO-LIEBER, Nicolina Silvana. O conceito de risco: Janus reinventado. In: MINAYO, Maria Cecília de Souza; MIRANDA, Ary Carvalho de (orgs.). Saúde e ambiente sustentável: estreitando nós. Rio de Janeiro: Ed. Fiocruz/Abrasco. 2002. p. 69-111.

MATA DIZ, Jamile Bergamaschine, DISCACCIATI, Ana Clara Gonçalves. Acesso à informação ambiental: por um novo paradigma de participação. Revista Eletrônica Direito e Liberdade, v.17, 2015, p.71 - 113.

MILARÉ, Édis. Direito do ambiente: A gestão ambiental em foco. Doutrina, jurisprudência, glossário. 7.ed., rev., atual., e reform. São Paulo: Editora Revista dos Tribunais. 2011.

MÜllerovÁ, H. et al. Public Participation in Environmental Decision-Making: Implementation of the Aarhus Convention. Praha: Ústav státu a práva AV ČR. 2013. 
Nations United Organization. Report of the Special Rapporteur on the promotion and protection of the right to freedom of opinion and expression, Frank La Rue, A/68/362, 4 September 2013.

PASTOR, Aitana de La Varga; GASÓ, Josep Ramon Fuentes. Las autoridades públicas ante las nuevas obligaciones en materia de información ambiental. Especial referencia a la difusión de información ambiental. In: Acceso a la información, participación pública y acceso a la justicia en materia de medio ambiente: diez años del convenio de Aarhus. Atelier, 2008. p. 187-224

RONCHA, I. M. da C. O Direito de Participação Pública na Tomada de Decisão Sustentável. Coimbra: Universidade de Coimbra. 2015.

SAMPAIO, José Adércio Leite; WOLD, Chris; NARDY, Afrânio José Fonseca. Princípios de direito ambiental. Belo Horizonte: Del Rey, 2003.

SANDS, Philippe. Principles of International Environmental Law. 2. ed. Cambridge: CUP, 2003.

VIEGAS, Thaís Emília de Sousa. Do silencio à crise: uma perspectiva do direito ambiental a partir da teoria da sociedade de risco. 2007. Dissertação (Mestrado em Direito). Centro de Ciências Jurídicas. Universidade Federal de Santa Catarina. Florianópolis, 2007. 